\title{
Two conceptions of the sources of conservatism in scientific research
}

Baptiste Bedessem ${ }^{1}$

\begin{abstract}
The issue of the conservatism of scientific research questions the nature and the role of the internal and external forces controlling the emergence of new research questions or problems, the exploration of risky directions of research, or the use of risky research methods. This issue has recently gained a new framing in connection with the growing importance of the peer-review process and of the social and economic pressures weighing on the funding of scientific research. Current literature then interrogates the external and internal features that promote what are described as conservative tendencies in scientific research. In this paper, I propose to contribute to this debate by clarifying what might be internal sources of conservatism in science; that is, that are inherent to the research process itself. I distinguish two possible understandings of the sources and manifestations of this internal conservatism. I first present a representational description of the nature and origin of conservatism in science, which brings to the fore the difficulties researchers find in setting aside their conceptual framework. I then offer for consideration a larger perspective on conservatism by arguing for the existence of a practical conservatism generated by all the dimensions of scientific activities. In this framework, conservatism in science can be explained by the tendency of all practices to close in on their own local objectives. I illustrate this view by reference to an historical episode: the discovery of the chemical nature of genes by Avery.
\end{abstract}

Key-words: scientific change; conservatism; practical turn; pragmatism; research policy.

\section{1-Introduction: conservatism as an epistemological issue}

In his 1945 report to president Roosevelt, the American scientist Vannevar Bush famously defended the idea that "scientific progress on a broad front results from the free play of free intellects, working on subjects of their own choice, in the manner dictated by their curiosity for exploration of the unknown"' (Bush 1945, p.13). This lyrical and idealized description of 1Università Ca'Foscari, Dorsoduro 3246, 30123 Venice . Email: baptiste.bedessemp@ gmail.com 
scientific activity, based on a somewhat naive valorization of scientists' individual freedom, may look very old-fashioned to contemporary eyes; however, the singular figure of the untrammeled researcher "exploring the unknown" by giving free rein to "curiosity" 2 is still abundantly used in many discourses defending a quite extreme principle of institutional autonomy for science, based on the freedom for individual ${ }^{3}$ researchers to set for themselves the directions of their inquiry. For instance, in a study dedicated to the conception that researchers have of the notion of "basic science", Calvert and Martin (2001, p. 12) found a "strong definitional emphasis on curiosity". In this perspective, "a basic researcher is someone who is just following his curiosity'. A typical illustration of this intellectual tradition is given by the 1974 Nobel Prize winner Christian de Duve, who insists on the epistemological value of individual curiosity in the following manner:

Fund the investigator, not the investigation. Do please remember, I beseech you, this selfevident yet rarely recognized truth that science, at least its spearhead called basic research, explores the unknown and is therefore unable, by definition, to predict how useful or profitable its discoveries will be. Rather than demanding assurances on this account that cannot possibly be honestly provided, put your trust in the investigator's skill, instinct, curiosity, and motivation (de Duve 2004, p. 21687).

The same idea was expressed more recently by a consortium of British scientists, led by Sir John Cadogan, which issued a report to the Learned Society of Wales defending the value of “curiosity-driven Blue Sky research":

Government must also accept without challenge that the socioeconomic advancement of humankind has its roots in science and technology, and that much of that has been curiosity-driven. However, the nature of all politics and politicians means it is easier for our paymasters to feel comfortable about the proclaiming of programs relating to Energy, Health, Materials, Climate Change, the Hydrogen Economy and so on, rather than to announce, let alone trumpet, that money is available for scientists to follow their curiosity in their own disciplines (Cadogan 2014, p. 2).

The curiosity of scientists is notably opposed to the constraints exerted by political and social demands, which orient research through a strategy of funding based on the selection of projects a priori considered significant (Wilholt 2010). In this framework, peer-review is often condemned as "conservative" (Lee 2015), in the sense that it would inhibit the emergence of radically new questions, problems, or objects of research. For instance, it has

2As recalled by Wilholt (2010) or Kummerfeld and Zollman (2016), their exists a rich tradition in classical philosophy of science which puts to the fore this need for researchers to benefit from a large degree of freedom in order to follow their "curiosity". A well-known position here is that of Polanyi (1962), but we might also refer to Popper's defense of free mutual criticism as an epistemological argument for a strong freedom and autonomy of science (Popper 1972, p. 33-35).

3Or, in a more sociologically realistic way, for small groups of researchers. 
been shown that the intellectual distance between the project submitted and the evaluator has a negative influence on the judgment of this latter (Boudreau 2016). This kind of argument then tends to oppose, at least implicitly, an external conservatism due to the institutional organization of scientific research ${ }^{4}$, to the supposed internal anti-conservatism, or anticonformism, of the research process itself, as it would be if led by free individuals.

The political impacts of such an epistemological position are significant. Indeed, when faced with the following pressing questions: "What will the research agenda for science be? How should we distribute funding amongst potential and ongoing scientific projects?" (Brown 2010, p. 131), it gives a very simple answer: "Fund people, not projects" (Ioannidis 2011) Yet, even if we accept that current funding arrangements may have such a conservative effect, it is still not at all certain that an alternative system promoting individual freedom would be less "conservative" in this common sense. This idea was notably developed by Kummerfeld and Zollman (2016, p. 1057), who suggested that "the scientific state of nature" (a hypothetical state where individual scientists are "left to their own devices") was "conservative". By this statement, they mean that the traditional idea of the "natural state of science" as "an endogenous source of diversity" (that they notably attribute to Bush 1945 and Polanyi 1962) is "misplaced". Indeed, they claim that there exists, within the scientific community, a "conservative influence" (p. 1058) that they define as a tendency to congregate on the apparently safer alternatives to solve a given problem or research question. Even if the method used by Kummerfeld and Zollman (mathematic modeling) is not fully convincing, this way of posing the problem seems to be relevant: are the institutional funding arrangements of science the only sources of its alleged conservatism? In which senses may the research process be considered as internally (anti)-conservative?

As we can see, the issue of conservatism in science is quite intricate, as it mixes together epistemological and political, descriptive and normative, dimensions. However, there currently exists an interesting renewal of this debate on conservatism in science as a social epistemology issue (Haufe 2013; Kummerfeld and Zollman 2016; Avin 2018; Harnagel 2018; Currie 2018a, 2018b; O'Connor 2018; Hessen 2018). I argue that this recent literature frames the discussions in an original way. Generally speaking, this framing is structured by two central elements: (i)conservatism is studied as a proper epistemological issue. It is clearly

4Characterized by a peer-review based competitive selection of projects

5The reader may find elsewhere more details on the exact sense of this kind of position in terms of funding schemes (Couée 2013; Braben 2008). Whatever the exact content of these proposals, the important point is that they are inherently biased by their ignorance of the internal sources of conservatism, as I state later in the paper. 
detached from its political meaning ${ }^{6}$; it is also, to a lesser extend, detached from sociological considerations about the institutional dynamics of collaboration, cooperation and interactions. More precisely, it puts to the fore the search for epistemological roots (that is to say, linked to the very nature of the research process itself) of the balance between "conservatism" and "novelty". (ii)There exists a relative axiological neutrality respect to the consequences of this conservatism ${ }^{7}$. A central idea seems to be that a fine description of the nature, the origins and the manifestations of conservatism in science is needed before judging in a normative way its epistemological consequences.

More precisely, we can identify three registers of interrogation among this contemporaneous social epistemology literature. First, it is not always clear what conservatism actually is (that is to say, the kind of behavior of researchers or the properties of the research process that are designated by this notion). Second, we may wonder which internal (linked to the research process itself) and external (linked to the funding arrangements) features promote conservative tendencies. Third, the question of the epistemological consequences of these conservative tendencies arises. Recently, various papers have tried to give answers to these different issues. Harnagel (2018) and Avin (2018) study the effects of funding schemes (and notably, of the peer-review based selection) on the "exploration" of a given epistemic landscape. O'Connor (2018) argues that "conservative science" is naturally selected in the highly competitive environment currently undergone by current scientific communities. Heesen (2018) considers the role of the credit and rewards economy of science in promoting or impeding the activity of "risk-taking" scientists. Adopting a wider perspective, Currie (2018a, 2018b) opposes the notion of conservatism to those of creativity and novelty, even if he grants that these are complex, polysemous notions. To him, they should nevertheless be understood as offering a good departure point for studying the epistemic properties of the very process of producing knowledge, taken as a collective endeavor. Taking this argument seriously, I propose, in this paper, to identify two possible conceptual frames describing the internal sources of this so-called conservatism, conceived of as inherent to the research process itself. I link the first one with Kuhn's model of scientific development, and I qualify it as representational conservatism. I then propose to complete it with a more general and more accurate conception of these internal conservative tendencies that I call practical

6This point is important, since the notion of conservatism has been mostly developed to capture a form of political or ideological tought, including by some influent sociologist of science, such as Mannheim (1986). 7It certainly would have been possible, and perhaps more relevant, to avoid using the confusing term of conservatism in this debate. For instance, the notion of "inertia" would have been well adapted to describe the epistemological features of the research process that this literature aims to capture. 
conservatism. A case study (the discovery of the chemical nature of genes by Avery) is used to illustrate this notion.

Let me note here that this contrast between representational and practical conservatism as conceptual frameworks draws on the classical criticism of the theory-focused perspective on scientific change, often associated to Kuhn's work and opposed to a more practice-oriented philosophy of science (Ankeny and Leonelli 2016). This practice-oriented philosophy of science notably recognizes that "experiments have a life of their own" (Hacking 1983, p. x), that is to say that the refinement or discussions of theories are not the only motor of scientific activities. However, my aim is not to give a formal criticism of Kuhn's views, but to propose two possible readings of this notion of conservatism by presenting two general ways of describing conservative behaviors.

\section{2-What is conservatism of scientific research?}

As it is most classically used in the literature, the "conservatism" of science generally refers to an alleged (spontaneous or institutional) tendency to give priority to problems, questions, methods, theories or practices already known, and/or considered as relatively safe, over unknown, poorly explored, and/or risky ones. As I remark in my introduction, the concept is abundantly used to qualify, in a critical perspective, certain features of contemporary scientific institutions. Interestingly, many national scientific agencies draw on a similar opposition when establishing their funding programs. As reported by O'Malley et al. (2009) and Haufe (2013), the NIH and the NSF establish a contrast between regular grant applications (R01 in NIH), and "exploratory", "risky", or "innovative" applications (R21 program of NIH and EAGER grants of NSF). These latter are explicitly described as promoting a form of novelty, whereas the former should be based on well founded hypothesis and well known methods.

Given this somewhat intuitive apprehension, it might appear that the notion of conservatism is not well defined, and that its meaning depends on the choice of opposing concept: conservatism may be opposed to creativity, innovation, revolution, etc ${ }^{8}$. In the current literature on conservatism in science, and as explicitly noted by Currie (2018a), the notion of conservatism in social epistemology makes sense as opposed to that of novelty (in testing a new method, formulating a new explanation or theory for a known phenomenon, collecting 
new data $)^{9}$. Like that of conservatism, this notion of novelty is not easy to assess, essentially because it is a matter of degree. However, importantly, I argue that it is not needed, in a first step, to have a much clearer definition of conservatism and novelty that the ones we find in current literature in social epistemology. Indeed, I make the hypothesis, with Currie (2018a), that the centrality of this balance between conservatism and novelty in the literature highlights the fact that some forces constrain, regulate, or limit the kinds of problem or question that are susceptible to being addressed by the scientific communities. The very existence of these constraints defines a first, minimal level of conservatism inherent to the process of scientific research as a collective endeavor. Reciprocally, the identification and characterization of these constraints (which is the main aim of this paper) will illuminate what might be called conservatism (and novelty) within the research process. One of the aim of this paper is then precisely to clarify the meaning of this antagonism conservatism $v s$. novelty in scientific research, as it is used in recent literature in social epistemology.

In the scope of this paper, I then focus on this singular dimension of the classical debate on conservatism by questioning the exact nature of the constraints that guide the kinds of problem that are worthy of being posed and resolved. Furthermore, I limit the scope of this interrogation to the internal sources of conservatism, inherent to the research process itself. By doing so, I aim to offer a more general perspective on the traditional, multidimensional debate on conservatism in science. Whereas many contemporary contributions try to identify specific, precise mechanisms, institutions, or cognitive behaviors that are held to promote a form of conservatism, this paper suggests a conceptual clarification of the notion by distinguishing two generic ways of describing the sources of the conservative tendencies inherent to the research process itself. I link the first to Kuhn's $(1962,1977)$ work. I show that this view of conservatism may be qualified as representational since it focuses on the scientists resistance to stepping outside of a given conceptual framework. Using a case study (that of Avery's discovery of the nature of genes), I suggest adopting a more general view on conservatism, by considering the role of the full range of scientific practices, in their multiple dimensions (instrumental, experimental, technical, theoretical), in the generation of a practical conservatism. Let me note that the kind of conservatism I am considering is taken as being anterior to any institutional scheme (for instance, funding schemes) regulating the functioning of the scientific community: in this sense, it corresponds to the internal

9We can cite here the Kuhnian antagonism between "tradition" and "innovation" (Kuhn 1977) and the opposition between "exploration" and "exploitation" mobilized by Polanyi (1962). 
conservatism of the (abstract) "scientific state of nature" of Kummerfeld and Zollman $(2016)^{10}$.

\section{3-Representational conservatism}

Many classical perspectives on conservatism in science were developed in the so-called "big systems" proposed in the 60-80s by philosophers and historians such as T. S. Kuhn (1962), I. Lakatos, or L. Laudan. These historicist theories of rationality aimed at "stress[ing] the depth of major historical changes and the resulting challenges to cumulative scientific progress" (Nickels 2017). It is usual enough to consider that in this framework, and in particular in Kuhn's perspective, the conservative forces (as I defined them previously) are mainly conceived as a matter of representation. It is the resistance of scientists to quit a given conceptual frame which constrains the emergence of new kinds of research problems, questions or objects. Reciprocally, scientific changes are "primarily generated and shaped by theoretical developments" (Ankeny and Leonelli 2016, p. 18). Even if the Kuhnian notion of paradigm is made manifest through a collection of techniques, protocols, and instruments (Masterman 1970), it indeed seems that in Kuhn's perspective, scientific changes are conceived of as being primarily the result of representational changes. Three major arguments can be used to justify this point:

First, the notion of epistemic "fertility" or "fecundity", central to Kuhn's explanation of why scientists are attached to the paradigms in which they work, is understood through the empirical adequacy of theories. This notion applies to concepts and theories, and may be understood as their capacity to pose new questions and/or to explain new phenomena (Schindler 2017). More generally, it reflects a classical link between experimentation and theories, where the first is seen exclusively as serving the justification or the refinement of the second. As explicitly stated by Kuhn, "much of the research undertaken within a research tradition is an attempt to adjust existing theories or existing observations in order to bring the two into closer and closer agreement" (Kuhn 1977, p. 233). This theoretical perspective on experiment (and more generally on scientific practices) was classically criticized by the socalled "practical turn" in the history and philosophy of science ${ }^{11}$, and notably by Ian Hacking's $(1983,1992)$ works on experimental practices. Through the idea that "experiments

10Let me also note that this paper focuses on the descriptive dimensions of the debate on conservatism, and sets aside the normative question of the relevance of designing scientific institutions and/or funding schemes which limit or promote conservatism.

11See section 5 for more details on this "practical turn". 
have a life of their own" (Hacking 1983, p. x), Hacking convincingly advocates a view of the research process more complex than of the mere construction and justification of theories, models, and hypotheses. By contrast, even if Kuhn recognizes that implicit knowledge plays an important role in the scientific process, and that the paradigms have technical and instrumental dimensions, his notion of fecundity seems to be very representational: it applies to theories as sets of articulated concepts and laws, and is measured in terms of the agreement between theoretical predictions and facts.

Second, the motor of change in Kuhn's theory is the accumulation of anomalies. An unexpected or problematic result is an anomaly if it conflicts explicitly with a "structurally central tenet of current scientific belief" (p. 237). Thus, anomalies are mainly representational, in the sense that they are opposed to current concepts, theories, or world views. Yet, authors affiliated to the "practical turn" have demonstrated that it is often our capacity of intervention and experimental manipulation that leads to old tools being abandoned and new tools adopted (Waters 2014). Consequently, the Kuhnian focus on theories as the motor of scientific changes (and respectively, as the cause of conservatism) constitutes a strongly debatable hypothesis.

Third, the notion of incommensurability, which evolved a great deal throughout Kuhn's intellectual trajectory, was finally interpreted as being a property of the networks of concepts. Sankey (1993) summed up this evolution by noting that "originally, incommensurability was a relation of methodological, observational and conceptual disparity between paradigms. Kuhn restricted the notion to the semantical sphere and assimilated it to the indeterminacy of translation" (p. 759). In particular, in his 1982 article entitled "Commensurability, Comparability, Communicability" (Kuhn 1982), Kuhn clarified the concept of incommensurability as a semantic problem, by assimilating it to the Quinean notion of the indeterminacy of translation. In this interpretation, two distinct (scientific) languages are incommensurable because the corresponding terms used do not have exactly the same reference in the real world. This perspective is considered quite radical since it implies the genuine incommensurability of networks of concepts constituting a theory as a representation of the natural world. Correlatively, paradigms are fully assimilated to world views, and scientific changes are primarily changes of representation. 
The question remains open as to whether this description of Kuhn's view of conservatism and change as being focused on theories (or representations) does full justice to the complexity and nuances of Kuhn's position. However, I argue that various aspects of Kuhn's work, and some of the classical and widespread interpretations of it, involve a specific perspective on the nature of the epistemic constraints guiding the formulation of research problems. If we consider seriously the criticisms of the authors of the "practical turn" in history and philosophy of science, these constraints are described in Kuhn's views as being rather representational, in the sense that they are linked to a network of explicit or implicit representations, concepts, and laws. Generally speaking, it is thus a certain representation of the world that determines the kind of questions the researchers consider as interesting. Likewise, it is a certain representation of the world that inhibits the emergence of new problems or objects of study. In the frame of this representational conservatism, the motor of scientific "innovation", and reciprocally the force of "tradition", are mainly explainable in terms of theories and representations ${ }^{12}$. In the vocabulary I proposed in my introduction, this means that the conservatism of the research process is primarily representational. In the following sections, I argue that this representational conservatism is not false, but rather incomplete, since it does not consider enough the fact that some dimensions of scientific practices might have a conservative influence independently of the existing theoretical or conceptual frame. I suggest that it should be incorporated (at least in part) into a more general perspective on conservatism that I call practical conservatism, which includes a wider range of aspects of scientific practices as being proper sources (and not just objects) of conservatism: creating and purifying a phenomenon in the laboratory, constructing an experimental instrument, collecting data, building a theory, a law or a model, etc. I begin with a case study: Avery's discovery of the chemical nature of genes.

\section{4-Case study: Avery's discovery of the chemical nature of genetic information}

\section{a-General presentation}

\footnotetext{
12Let me insiste again on the following point: the so called "practical turn" in history and philosophy of science often takes Kuhn's work as the a typical instance of a "theory-centered" perspective on scientific development. Clearly, this strategy operates a certain reduction of the numerous (and sometimes contradictory) writings proposed by Kuhn. It is clearly possible to nuance this attribution of a "theory-centered" perspective to Kuhn, but I do argue, with many authors (see, for recent instances, Soler 2014 or Ankeny 2016) that in a spectrum going from Kuhn to contemporaneous philosophers of science, there is a certain trend from a representational to a practical perspective on scientific development. My contrast between representational and practical conservatism mirrors this well accepted opposition.
} 
Avery's work is well known by historians of science as a case of an important discovery (that the DNA, and not the proteins, carries the genetic information) which was ignored, in a sense that I will hereafter clarify, by contemporary scientists (Morange 2000, p. 45-53). Avery was working at the Rockefeller Institute of New York on the characterization of pneumococcus (the bacteria involved in tuberculosis). He notably studied the structure of the bacterial capsid, which carries the molecules responsible for the virulence of pneumococcus. By 1930, Avery and his team began to focus on a strange phenomenon, called "transformation", which was first observed by Griffith in 1928. The concept of "transformation" refers to the ability of virulent pneumococcus, carrying a capsid (named $\mathrm{S}$ pneumococcus), to transfer the ability to synthesie the capsid to non-virulent ones (named $\mathrm{R}$ pneumococcus). The most classical transformation experiment is the following: by adding a sample of dead $\mathrm{S}$ pneumococcus to live $\mathrm{R}$ pneumococcus, we can generate $\mathrm{S}$ pneumococcus - that is to say, bacteria which cause tuberculosis. In other words, in S (virulent) pneumococcus there is a chemical "transformative principle" which can be transferred to R (non-virulent) pneumococcus and gives it the ability to generate a capsid and become virulent. After ten years of delicate experimental work, Avery and his co-workers published a famous paper showing that the transforming principle was a nucleic acid, and not a protein (Avery 1944). Retrospectively, this result had a double impact: for the understanding of the transformation phenomenon itself and, more largely, for genetic and fundamental biology. At the time, the chemical nature of the molecule carrying genetic information was not precisely known. Most scientists thought it was a mix of DNA and proteins, but the exact role of each of these components was not known (Wyatt 1972, p. 88). The aim of this fourth section is to report the noteworthy way in which this discovery was not integrated into scientific practices, despite being considered theoretically important.

\section{b-Analysis of Avery's work}

The essential part of Avery's 1944 article is dedicated to the description of the methods used to isolate and characterize the gene product responsible for the transformative power. In it, we find a detailed presentation of the purification protocol (p. 138-144), and of a range of chemical tests aiming at identifying the molecule obtained: its general chemical properties (p. 145), its elementary composition and the effects of different kinds of enzymes (p. 146-149), immunological analysis (p. 150), physical study (ultracentrifugation, electrophoresis), and quantification of biological activity (p. 151). Interestingly, the wider interest of Avery's result for fundamental biology is neither evoked in the title, nor in the abstract. The discussion rapidly notes that "the phenomenon [can] be interpreted from a genetic point of view" ( $\mathrm{p}$. 
155), by considering "the inducing substance" as a gene, and "the capsular antigen which is produced in response to it (...) as a gene product". Yet, the reference made to the question of the transmission of the characters in the introduction (p. 137) shows that the authors knew perfectly well that their results were of interest beyond their implication for the phenomenon of transformation itself. Furthermore, Wyatt (1972) presents numerous historical proofs showing that even if Avery did not insist, in his article, on the importance of his discovery for fundamental genetics, he "was well aware of [its] implication" (p. 87). By examining the private correspondence of Avery, he notes that Avery explicitly considered that he might have isolated "a pure gene in the form of deoxyribonucleic acid" (Idem).

The perspective for future work he gives at the end of his article are nonetheless restricted to technical considerations about the production of the transformation phenomenon. He notes that it "would be of interest to know the relation between the rate of reaction and concentration of the transforming substance; the proportion of cells transformed to those that remain unaffected in the reaction system". His aim is thus explicitly to find a way to "induce transformation in a suspension of resting cells under conditions inhibiting growth" (pp. 153154). Avery's over-insistence on these technical goals may seem surprising in comparison with the general importance of his observations for fundamental biology. Interestingly, Avery effectively followed the program he proposes in his article and, during the following years, tried to improve the protocol of transformation of pneumococcus as a laboratory phenomenon (Morange 2000, p. 53).

\section{c-Reception of Avery's work}

Surprisingly, it is also the case that Avery's discovery had few consequences on genetic research. In his study of the reception of Avery's work, Wyatt clearly shows that the different scientific communities which could have been interested by Avery's results about DNA largely ignored them in the definition of their research programs. Notably, the geneticists (such as Beadle and Tatum, Morgan's group, or the Phage Group) "were not greatly influenced by the news" (p. 87), even if they were all well aware of Avery's work. Large symposiums dealing with heredity (such as that at Cold Spring Harbor in 1946) just mentioned the results in passing. On the other hand, all these scientists recognized the theoretical importance of Avery's discovery. For instance, in "semi-popular" scientific 
journals (such as American Scientist), many articles were written to report it as "an extremely fundamental contribution to all biological sciences" (p. 88, my emphasis). However, Avery's result was rapidly forgotten by the scientific community. It was independently re-assessed eight years later by Hershey and Chase (1952), in a research program ${ }^{13}$ which was explicitly designed to identify the chemical nature of the genes.

\section{d-Discussion: "post-maturity” and scientific conservatism}

This episode is then characterized by a highly paradoxical situation, where a discovery whose potential importance is not ignored by scientists is nonetheless not taken into account as a possible new direction of research. Retrospectively, the behavior both of Avery and of the scientific community as a whole is quite surprising. Indeed, in 1944, the question of the chemical nature of genetic information was not in practice considered as an interesting problem for scientists. Certainly, it was considered as an important question from a theoretical perspective. But it was not a research question motivating scientific practice. Retrospectively, the reception of Avery's result thus demonstrates a significant lack of curiosity on the part of researchers. Contrary to a model of scientific development focused on the "exploratory" dynamics, the researchers did not use Avery's observation to define a new object of study - DNA. The geneticists did not formulate a new research question, and Avery himself remained focused on his original question - the transformation phenomenon. In other words, Avery's episode shows up a tendency to conservatism within the community of geneticists and biologists in the 1940's.

Various explanations of this conservative behavior could be given. Morange (2009) highlights certain sociological, institutional, and intellectual reasons for the fate of Avery's discovery (p. 3-4). However, none of them can give a good account of the surprising fact that "if the experiment of Avery was not accepted, it was not rejected either" (Idem). More precisely, historians of science have to face a strange situation where a discovery recognized as theoretically important is, at the same time, ignored within scientific practice. To deal with this mysterious behavior, Morange (2000) (p.48) refers to the distinction made by Wyatt (1972) between "information" and "knowledge". Elsewhere in his history of molecular biology, he mobilizes the notion of "post-maturity", introduced by Zuckerman and Lederberg (1986) to describe similar kinds of events, where, in their practices, scientists ignore for a long time an important theoretical question. He notably uses it in the case of Beadle and 
Tatum's work on the link between genes and enzymes (p. 31-40), and to explain the late discovery of RNAm (p.188). This concept is then mobilized to qualify an occasional "lack of curiosity" on the part of scientists (p.192). Clearly, this kind of intuitive notion of "postmaturity" aims at describing a certain form of conservatism that is inherent to scientific development.

Does the representational conservatism previously presented sufficiently well capture the form of conservatism manifest in Avery's case? Ignorance of Avery's discovery was clearly not due to representational barriers. On the contrary, the knowledge of the chemical nature of genes perfectly matched the conceptual framework grounding molecular biology and genetics. Furthermore, it would have been technically possible for geneticists to take it as a source of interesting research problems: how could DNA be the support of genes? What link subsists between genes and proteins? The work of the members of the "Phage Group", for instance, constitutes a good justification of this idea: they independently posed and solved the problem of the nature of the genes a few years later, without having any knowledge of Avery's work (Morange 2000). Technical or experimental obstacles are thus not sufficient to explain the disinterest for Avery's discovery. If neither representational framework nor technical barriers are the causes of this lack of scientific curiosity for Avery's result, how might we explain it? In the next section, I propose the notion of practical conservatism as a descriptive tool for understanding this particular dynamic of the research process.

\section{5-Practical conservatism}

The so-called "practical turn" or "practical trend" in the philosophy of science aims at providing a more exhaustive picture of the scientific dynamics than the allegedly theoryfocused classical reading of the historical evolution of knowledge and scientific activities (Soler 2014). Even if it is not clear what intellectual movement this "practical turn" aims at replacing, it is quite common to consider that it is characterized by a (more explicit) desire to study scientific practices in all their diversity (Nordmann 2014). A major source of this "practical turn" is the so-called "new experimentalism" notably launched by I. Hacking. By considering that "experiments have a life of their own" (Hacking 1983, p. x), this philosophical program insists that the experimental and technical dimensions of scientific activities (interventions) should not be considered as mere tools of justification or the refinement of theories, concepts, or models (representations). One of the current challenges of the "practical turn" is thus to consider the integration of representation and intervention as 
distinct but interconnected dimensions of scientific activities (Woody 2014). In order to ground the notion of practical conservatism, I will retain here the framework proposed by Chang (2014) for considering this integration of scientific activities into hierarchical and interconnected systems of practice. For Chang, all scientific activity, whether it consists in technical, instrumental, experimental, or mental operations (manipulating live cells, lighting a match, testing a microscope, isolating a phenomenon in the laboratory, defining a concept) has to be thought as having both (an) external function(s) and an internal objective. Its internal objective constitutes its proper end, and its external function describes how it serves a larger goal. For instance, the activity ${ }^{14}$ of lighting a match may be realized in order to light a Bunsen burner. This last activity (lighting a Bunsen burner) also has an external function: for instance, to "get a combustion-analysis of an organic compound" (Chang 2014, p. 73). The important point is that the internal objective of an activity (to light a Bunsen burner) constitutes the external function of the subsequent ones (to light a match). Following Chang's views, all scientific activities thus belong to one or various systems of practice, which are structured into networks of hierarchically-organized objectives ${ }^{15}$. This being the case, each system of practice may be thought as being embedded in others; furthermore, distinct, independent systems of practice may coexist. For instance, theoretical physics (as a system of practice) co-exists with cellular biology (as another system of practice). In some cases, two systems of practices may be connected through a shared activity. Typically, an experimental technique may be used in different contexts, for very distinct purposes. For instance, the activity of using electronic microscopy may be shared by cellular biology, chemistry, and physics.

Let us return to Avery's work. In this case, a general objective of the system of practice in which it was embedded may have been the study of the pathogenic power of pneumococcus. Within this general framework, Avery dedicated a sub-system of practices to the study of the transformation phenomenon. Within this sub-system of practice, two distinct objectives then motivated two sub-sub-systems of practice. The first was the isolation and purification of the transformation phenomenon as a laboratory object. This notably passes through identification of the culture media which favor it. The second was the search for the transformative

14Chang (2014) distinguishes the notions of act and activity, the last one implying "a routinized and repeated performance of the act, which the agents involved carry out according to a reasonably fixed set of rules governing their attempts to achieve the aim of the activity" (p. 73).

$15 \mathrm{~A}$ useful graphic representation of Chang's notion of system of practice is presented in the commentary of Chang's text by L. Soler and R. Catinaud (Soler 2014, p. 80-92). 
principle, using many distinct chemical and biological techniques. It led to the isolation of DNA as the molecular support of heredity. If we take a step back, we may note that Avery's system of practices coexisted with other systems of practices in the more general frame of modern biology (including genetics, molecular biology and biochemistry). I may cite the classical (Mendelian) geneticists working on the inheritance of characteristics; for instance, Morgan's group and its famous experiments on Drosophila. Another system of practices was the one developed by the physicians of the so-called Phage Group working on the molecular mechanisms of heredity in the bacteriophage Lambda (Mullins 1972).

In this framework, how can we explain the conservative tendency manifested by the geneticist community after Avery's discovery? In a nutshell, we could say that the most local objectives pursued by Avery (isolating and studying bacterial transformation as a laboratory phenomenon) was prioritized over the formulation of a new research question (for instance, the structure of DNA and its exact role in heredity), even if this latter would have had a wider scope of interest (here, the comprehension of the molecular mechanisms of heredity, or the even broader project of the molecular description of life by molecular biology). As a consequence, the local system of practice undertaken by Avery was given priority both over more general ones, and over coexisting ones (for instance, that developed by the Phage Group).

In other words, we could say that Avery and the geneticist community favored the stability of the local system of practices they were embedded in over the progress of co-existing or radically new research questions. For instance, Avery made the choice to focus on the purification and isolation of transformation as a laboratory phenomenon, by designing new protocols which aimed at making it visible. By doing so, he gave priority to the activities he had first developed to study bacterial transformation. Similarly, the geneticists' community remained focused on the internal objectives of their own system of practices. In this case, the movement of closure of the systems of practice on their initial objectives seems to be the cause of the conservative tendency identified in Avery's case. My thesis is that this movement may be the manifestation of a practical conservatism, and that this practical conservatism is an inherent feature of the research process. Practical conservatism may thus be characterized in the following terms. All scientific activities, from the most technical to the most conceptual, theoretical, or representational ones, take place in a system of hierarchicallyorganized objectives, which constitutes a system of practice (or more precisely, a 
superposition of systems of practice $)^{16}$. The existence of a practical conservatism implies that these systems of practice tend to favor their own stability - that is to say, the maintenance of the existing practices. To say it another way, the local practices scientists are currently leading tend to have priority in defining the problems or research questions to be pursued. The important point here is that this conservatism is not only caused by the representational frame, but is generated by all kinds of scientific practices. For instance, the ignorance of Avery's discovery by the geneticists and by Avery himself was not due to an intellectual barrier, but to a preference given to the systems of practice which were currently being pursued. These systems of practice included very technical activities, such as the isolation of the bacteria transformation as a laboratory phenomenon ${ }^{17}$.

\section{6-Representational conservatism as a particular case of practical conservatism}

As a principle of maintenance of the systems of practice, practical conservatism applies at all levels of these the systems of scientific practices, from the most technical to the most theoretical dimensions of scientific activities. As a consequence, I argue that the representational conservatism I attributed to Kuhn may be conceived, at least for a part, as a particular case of this practical conservatism. Indeed, the resistance of scientists to abandoning a certain conceptual framework may be interpreted as a priority given to the most general, theoretical, conceptual objectives shared by all the systems of practice which develop in the framework of a given paradigm (in a nutshell, the development or refinement of the intellectual framework structuring this paradigm). For instance, in modern biology, it is wellknown that scientists tend to give priority to reductionist approaches - for example in explaining diseases - over more organicist or holistic ones (Marcum 2010). Obviously, as already noticed by Kuhn, this conservatism is far for from being systematically negative from an epistemological point of view ${ }^{18}$.

As a consequence, representational and practical conservatism are not entirely antagonistic conceptions of conservatism in science. On the contrary, the reference to practical

16It is important to insist on the fact that each system of practice is itself included in larger ones, motivated by larger-scope goals.

17Let me repeat that my objective is not normative: I do not aim at judging the epistemological consequences of this conservatism. My goal is only to describe a possible source of conservatism in science, this concept of conservatism being understood in the broad and classical sense given in the introduction and in section 2 .

18Indeed, the resistance of scientists to abandoning a certain paradigm may be, in part, explained by its proper fecundity, in the classical sense of this term (Schindler 2017). 
conservatism may be understood as a more general perspective on conservatism: as the most representational parts of scientific research (elaboration of theories, of conceptual frameworks, etc.) are also scientific practices (Soler 2014), I argue that a practical conservatism may apply to them. However, this does not exclude that there may be a purely representational conservatism, specifically linked to the (psychological, intellectual) constraints exerted by a conceptual framework on scientific activities. Finally, practical and representational conservatism constitute two complementary conceptions of the internal sources of conservatism in science.

As I stated previously, this contrast between practical and representational conservatism echoes a traditional divide between a theory-oriented and a practice-oriented philosophy of science. Consequently, Avery's case might find an interpretation in some recent contributions which aim at giving a description of scientific change that takes into account the diversity of the social, material, and institutional conditions of the research process. For instance, the concept of scientific "repertoire" is defined by Ankeny and Leonelli (2016) as an "assemblage of skills, behaviors, and material, social, and epistemic components that a group may use to practice certain kinds of science" (p. 18). As this notion is explicitly conceived as broader than that of the "system of practice" (Chang 2014) which forms the conceptual basis of our argument, it seems that Avery's case could surely be interpreted by using this notion of repertoire. However, my aim is not to give an exhaustive description of all the dimensions of the dynamics of scientific change: I focus on what I call the internal sources of conservatism, defined as those inherent to the research process itself ${ }^{19}$.

\section{7-Discussion: internal and external sources of conservatism}

\footnotetext{
19Let me note here that this description of a "practical conservatism", which identifies some internal constraints on the definition of research problems, should be completed in the future by a more formal account of what is a significant problem. It is not the aim of this paper to go further in this direction, but I think that the pragmatist tradition, and notably Dewey's views on the logic of scientific inquiry (Dewey 1938), could bring an interesting perspective on Avery's case, and on practical conservatism in general. For Dewey indeed, the notion of "problem" makes sense in the very local context of a given practice. A problem is formulated on the basis of an "indetermination" met in the course of a concrete practice, and which can take a large diversity of forms: conceptual doubt, technical difficulty, surprising result, etc. The important point is that these indeterminations are formulated into well-posed problems only if they constitute an obstacle for the pursuit of the practice at stake. This offers a possible interpretative frame to Avery's episode: the issue of the nature of genes was not considered as an interesting problem since its resolution was not useful for the current practices led by geneticists. This reference to pragmatism might then be a useful tool to conceptualize the notion of a "problem" in a way that would be compatible with my description of a "practical conservatism".
} 
To conclude, let me clarify this last point. This article may be taken as an attempt at clarifying the issue of the conservatism of scientific research. In this framework, I mainly propose to renew reflection on the internal source of conservatism by introducing the notion of practical conservatism, which I contrast with the representational conservatism, thus hoping to complete the concept. This work is mainly descriptive, and does not aim at giving normative assessments about the way science should be organized to limit the (supposed) negative epistemic consequences of conservatism.

However, the identification of the internal sources of conservatism is a necessary step for conceiving the impact of funding arrangements on the production of knowledge. As I remarked in my introduction, many criticisms of the contemporary governance of science insist on the fact that the current ways of governing science would impoverish research by promoting mainstream or safe alternatives. Notably, the selection of projects using a peerreview process is commonly accused of being conservative and inefficient (Haufe 2013; Boudreau 2016; Avin 2018). The common implicit hypothesis shared by these positions is that scientists would do better if left alone (Kummerfeld and Zollman 2016). In other words, on such a view the sources of conservatism are seen as being mainly external to the research process, in the sense that they are mainly due to the contingent features of the institutional organization of science. It has to be noted that this position is anchored in a rich philosophical tradition which insists on the diverse epistemological benefits that freedom and autonomy would confere to scientific research (Wilholt 2010). Consequently, contemporaneous works on this notion of conservatism have an importance for fundamental philosophy of science, noably because it implies to discuss the roles that free curiosity play and should play in the research process. Against these views which insist on the external sources of conservatism, the analysis presented here aims at showing that there may also be strong internal sources of conservatism, inherent to the research process. In a more practical dimension, the question remains open of deciding how the identification of these sources of conservatism may influence reflection on science policy.

\section{References}

Ankeny, R. A. and Leonelli, S. (2016). Repertoires: A post-Kuhnin perspective on scientific change and collaborative research. Studies in History and Philosophy of Science, 60:18-28. 
Avery, O. T. and MacLeod, M. M. (1944). Studies of the chemical nature of the substance inducing transformation of pneumococcal types. J. Exp. Med., 79, 137-158.

Avin, S. (2018). Policy considerations for random allocation of research funds. Roar Transactions, 6(1).

Boudreau, K. J., Guinan, E. C., Lakhani, K. R. and Riedi, C. (2016). Looking across and looking beyond the knowledge frontier : Intellectual distance, novelty, and resource allocation in science. Manage Sci., 62(10), 2765-2783.

Braben, D. W. (2008). Scientic Freedom. The Elixir of Civilization. Hoboken: WileyInterscience

Brown, M. J. (2010). Genuine problems and the significance of science. Contemporary Pragmatism, 7(2), 131-153.

Bush, V. (1945). Science, The Endless Frontier. Report to the president Roosevelt.

Cadogan, J. (2014). Curiosity- driven Blue Sky Research: a threatened vital activity? Report to The Learned Sociey of Wales.

Calvert, J. and Martin, B. R. (2001). Changing conceptions of basic research. Workshop on Policy Relevance and Measurement of Basic Research, OECD.

Chang, H. (2014). Epistemic Activities and Systems of Practice: Units of Analysis. In Soler, L. and Zwart, M. L. and Israel-Jost, V. (Eds.), Science after the practice turn in the Philosophy, History, and Social Studies of Science (p. 67-80). Abingdon: Routledge.

Couée, I. (2013). The Economics of Creative Research. EMBO reports, 14(3):222-225.

Currie, A. (2018a). Creativity, Conservativeness and the Social Epistemology of Science. Studies in History and Philosophy of Science. https://doi.org/10.1016/j.shpsa.2018.11.001

Currie, A. (2018b). Existential Risk, Creativity and Well-Adapted Science. Studies in History and Philosophy of Science. https://doi.org/10.1016/j.shpsa.2018.09.008

de Duve, C. (2004). My love affair with insulin. JBC, 279, 21679-21688.

Dewey, J. (1938). Logic. The Theory of the Inquiry. Boston: Henry Holt and Co.

Fang, F. C. and Casadevall, A. (2016). Research funding: the case for a modified lottery. mBio, 7(2), e00422-16.

Gläser, J. and Velarde, K. S. (2018). Changing funding arrangements and the production of scientific knowledge : Introduction to the special issue. Minerva, 56, 1-10.

Hacking, I. (1983). Representing and intervening. Cambridge: Cambridge University Press. 
Hacking, I. (1992). The Self-Vindication of the Laboratory Sciences. In Pickering, A. (Ed.), Science as practice and culture. Chicago: University of Chicago Press.

Harnagel, A. (2018). A Mid-Level Approach to Modeling Scientific Communities. Studies in the History and Philosophy of Science. https://doi.org/10.1016/j.shpsa.2018.12.010

Heesen, R. (2018). The Credit Incentive to Be a Maverick. Studies in the History and Philosophy of Science. https://doi.org/10.1016/j.shpsa.2018.11.007

Haufe, C. (2013). Why do funding agencies favor hypothesis testing? Studies in History and Philosophy of Science, 44, 363-374.

Hershey, A. D. (1952). Independent functions of viral protein and nucleic acids in growth of bacteriophage. J. Gen. Physiol., 36, 39-56.

Ioannidis, J. P. A. (2011). Fund people, not projects. Nature, 477, 529-531.

Kuhn, T. S. (1962). The Structure of Scientific Revolutions. Chicago: University of Chicago Press.

Kuhn, T. S. (1977). The Essential Tension. Selected Studies in Scientific Tradition and Change. Chicago: University of Chicago Press.

Kuhn, T. S. (1982). Commensurability, Comparability, Communicability. Philosophy of Science, 2, 669-688.

Kummerfeld, E. and Zollman, K. J. S. (2016). Conservatisme and the scientific state of nature. The British Journal for the Philosophy of Science, 67(4), 1057-1076.

Lee, C. J. (2015). Commensuration bias in peer review. Philosophy of Science, 82(5), 12721283.

Mannheim, K. (1986). Conservatism: A Contribution to the Sociology of Knowledge. David Kettler Volker Meja and Nico Stehr (eds.). London: Routledge.

Marcum, J. A. (2010). Cancer: complexity, causation, and systems biology. Matière Première, Revue d'épistémologie, 1, 127-148.

Masterman, M. (1970). The Nature of a Paradim. In I. Lakatos and A. Musgrave (Eds.), Criticism and the Growth of Knowledge. Cambridge: Cambridge University Press.

Morange, M. (2000). A History of Molecular Biology. Cambridge, MA: Harvard University Press.

Morange, M. (2009). History of Molecular Biology. In Encyclopedia of Life Sciences, Hoboken: Wiley \& Sons, Ltd.

Mullins, N. C. (1972). The development of a scientific specialty : The phage group and the 
origins of molecular biology. Minerva, 1, 51-82.

Nickels, T. (2017). Historicist Theories of Scientific Rationality. In The Stanford Encyclopedia of Philosophy (Summer 2017 Edition).

Nordmann, A. (2014). Comments on "Science after the Practice Turn in the Philosophy, History, and Social Studies of Science" (Soler et al., eds). Notre-Dame Philosophical Reviews.

O'Connor, C. (2018). The Natural Selection of Conservative Science. Studies in the History and Philosophy of Science. https://doi.org/10.1016/j.shpsa.2018.09.007

O'Malley, M., Elliot, K. C., Haufe, C. et Burian, R. M. (2009). Philosophies of Funding. Cell, 21:611-615.

Polanyi, M. (1962). The Republic of Science: its Political and Economical Theory. Minerva, $1,54-74$

Popper, K. R. (1972). Objective knowledge: An evolutionary approach. Oxford: Clarendon.

Sankey, H. (1993). Kuhn's changing concept of incommensurability. British Journal of the Philosophy of Science, 44, 759-74.

Schindler, S. (2017). Theoretical Fertility McMullin-Style. European Journal for the Philosophy of Science, 7(1), 151-173.

Soler, L., Zwart, M. L. and Israel-Jost, V (Eds.). (2014). Science after the practice turn in the Philosophy, History, and Social Studies of Science. Abingdon: Routledge.

Waters, C.-K. (2014). Shifting Attention From Theory to Practice in Philosophy of Biology. In M.C. Galavotti, D. Dieks, W.J. Gonzalez, S. Hartmann, T. Uebel, and M. Weber (Eds.), New Directions in the Philosophy of Science (pp. 121-139). Berlin: Springer International Publishing.

Wilholt, T. (2010). Scientific freedom: its grounds and their limitations. Studies in History and Philosophy of Science, 41, 174-181.

Woody, A. I. (2014). "Chemistry's Periodic Law: Rethinking Representation and Explanation After the Turn to Practice". In Lena Soler, Sjoerd Zwart, Michael Lynch, and Vincent IsraelJost (Eds.), Science after the Practice Turn in the Philosophy, History, and Social Studies of Science (p. 123-151). Abingdon: Routledge

Wyatt, H. V. (1972). When does information become knowledge ? Nature, 235, 86-89.

Zuckerman, H. and Lederberg, J. (1986). Postmature scientific discovery. Nature, 324, 629631. 